http://jmscr.igmpublication.org/home/ ISSN (e)-2347-176x ISSN (p) 2455-0450 crossref DOI: https://dx.doi.org/10.18535/jmscr/v8i1.02

\title{
Weekly versus Biweekly High Dose Rate Brachytherapy Schedules in Carcinoma Cervix Following Concomitant Chemoradiation with Cisplatin
}

\author{
Dr Avni Kachhwaha1, Dr H. S. Kumar², Dr M. R. Baradia ${ }^{3}$, Dr Neeti Sharma ${ }^{4}$, \\ Dr Shankar Lal Jakhar, Dr Kamlesh Kumar Harsh ${ }^{6}$ \\ ${ }^{1}$ Resident, Radiation Oncology Department, ATRCTRI, S. P. Medical College, Bikaner \\ ${ }^{2}$ Senior Professor, Radiation Oncology Department, ATRCTRI, S. P. Medical College, Bikaner \\ ${ }^{3}$ Director, Radiation Oncology Department, ATRCTRI, S. P. Medical College, Bikaner \\ ${ }^{4}$ Professor and Head, Radiation Oncology Department, ATRCTRI, S. P. Medical College, Bikaner \\ ${ }^{5}$ Associate Professor, Radiation Oncology Department, ATRCTRI, S. P. Medical College, Bikaner \\ ${ }^{6}$ Assistant Professor, Radiation Oncology Department, ATRCTRI, S. P. Medical College, Bikaner \\ Corresponding Author
}

\section{Dr H S Kumar}

Senior Professor, Radiation Oncology Department, ATRCTRI, S. P. Medical College, Bikaner

\begin{abstract}
Objective: The main objective of brachytherapy in carcinoma cervix is to deliver a lethal dose to tumour cells without inducing unacceptable damage to the surrounding normal tissue. Because the absorbed dose falls off rapidly, higher doses can be delivered safely to the targeted tissue over a short time. The aim of this study is to compare disease response, acute and late treatment related toxicities between two HDR brachytherapy regimens.

Material and Methods: 50 biopsy proven and registered FIGO stage IB2-IIIB cases of carcinoma cervix treated with concurrent CT (Inj. cisplatin $40 \mathrm{mg} / \mathrm{m}^{2}$ weekly) + EBRT up to 50Gy are included and randomised into two arms. In Arm A (control), HDR of 7.5Gy x 3\# (weekly) is delivered to patients. In Arm $B$ (study), HDR of 5.5Gy x 5\# (biweekly) is delivered to patients. Disease response is evaluated by WHO criteria at the end of treatment, then at 1, 3 and 6 months to complete their 1 year follow up. Treatment related toxicities are also evaluated by RTOG guidelines at 1,3 and 6 months up to 1 year.

Results: At $1^{\text {st }}$ month, 96\% in Arm A and 92\% in Arm B, at $3^{\text {rd }}$ and $6^{\text {th }}$ month $84 \%$ in Arm A and $76 \%$ in Arm $B$ shows complete response. At 1 year DFS is $84 \%$ in Arm A and 68\% in Arm B. In late toxicity, Grade III and $I V$ vaginal fibrosis and rectal complications were seen in $16 \%$ and $4 \%$ respectively in both arms. Grade III and IV bladder complications were observed in 0\% in Arm A and 8\% in Arm B.

Conclusion: This study suggests that both HDR fractionation schedules proved safe and well tolerated by patients. So, any of the regimens can be used depending upon patient factors and work-load of the institute.

Keywords: Ca cervix, HDR brachytherapy, disease response, late treatment toxicity, disease free survival.
\end{abstract}

\section{Introduction}

Carcinoma of the uterine cervix (cervical cancer) is the second most common malignancy and fourth leading cause of deaths seen in Indian females. ${ }^{[1,2]}$ In India 60,000 death occur every year due to carcinoma cervix. ${ }^{[3]}$

However, cervical cancer is slow growing, so it's progression through precancerous changes 
provides opportunities for prevention, early detection and treatment. Most women diagnosed with precancerous changes in the cervix are in their 20s and 30s, but the average age of women when they are diagnosed with cervical cancer is the mid 50s. ${ }^{[4]}$

The risk of developing cervical cancer is associated with infection with HPV (Human Papilloma Virus). Other risk factors include early sexual contact, multiple sexual partners and OCPs. ${ }^{[4]}$

Rates of invasive cervical cancer are particularly high in Latin America, southern and eastern Africa and India. It is more common in rural (about $65 \%$ ) than urban (about 35\%). ${ }^{[4]}$

The risk of cervical cancer is increased in prostitutes and in women who have first coitus at a young age, have multiple sexual partners, multiparous, use of oral contraceptives for more than 10 years, smokers, lower socioeconomic status, poor genital hygiene, immunodeficiency, or bear children at a young age.

Patients of cervical cancer can present with pelvic pain, per vagianl discharge, per vaginal bleeding (mainly post coital). Renal failure due to hydronephrosis is the most common cause of death in cervical cancer patients. ${ }^{[4]}$

Patients of cervical cancer in India usually present in FIGO stage II (35\%), or in stage III (43\%) with $88 \%$ of total cases having squamous histology. ${ }^{[5]}$

The main objective of radiotherapy is to deliver a lethal dose to tumour cells without inducing irreparable or unacceptable damage to the surrounding normal tissue. The most common form of irradiation is the use of external beam radiation, mainly photons. American Brachytherapy Society (ABS) recommends use of brachytherapy whenever possible for completion of successful treatment of cervical cancer with radiotherapy. ${ }^{[6]}$

The American Brachytherapy Society recommends use of multiple intracavitary brachytherapy insertions to allow progressive tumour volume reduction, allowing more effective disease coverage with the subsequent application.
When external beam irradiation and high dose rate (HDR) intracavitary brachytherapy are combined, the goals are to treat Point A (or Point $\mathrm{H}$ ) to a low dose rate (LDR) equivalent of 80-85Gy for earlystage disease and 85-90Gy for advanced stage. Every attempt is made to keep the bladder dose below low dose rate (LDR) equivalent of $80 \mathrm{~Gy}$ and the rectal dose below $75 \mathrm{~Gy} .{ }^{[7]}$

Total treatment duration (EBRT \& ICBT) must be less than 8 weeks. ${ }^{[8]}$ Several studies have suggested that there may be as much as $1 \%$ decrease in survival and local control for each extra day of treatment beyond a total treatment time of 55 to 60 days. ${ }^{[9]}$

ABS recommend maintaining fraction size to $<7.5 \mathrm{~Gy}$ for each application of brachytherapy ${ }^{[10]}$ with 4 to 8 fractions, because higher dose per fraction are associated with higher toxicities.

\section{Material and Methods}

The study was carried out in department of Radiation Oncology at Acharya Tulsi Regional Cancer Treatment and Research Institute (ATRCTRI), Bikaner.

50 patients with biopsy proven cases of carcinoma cervix registered at our institute from March 2018 to March 2019 were included and received concurrent CT (inj. cisplatin $40 \mathrm{mg} / \mathrm{m}^{2}$ wkly) + EBRT up to 50Gy then, randomised into two groups of 25 patients each by using the website (http:/www.randomisation.com) of two HDR ICBT schedules.

$$
\begin{aligned}
& \text { Arm-A: } 3 \text { x } 7.5 \text { Gy (weekly) } \\
& \text { Arm-B: } 5 \text { x } 5.5 \text { Gy (biweekly) }
\end{aligned}
$$

\section{Inclusion Criteria}

1) FIGO Stage IB2-IIIB.

2) Histo-pathologically proven squamous cell carcinoma of cervix.

3) Previously untreated cases.

4) ECOG performance status (0-2).

5) Age $<70$ years.

6) Adequate baseline organ function (Hematological, renal function test \& liver function test). 
7) Patient must be fit for HDR.

8) Informed consent.

\section{Exclusion Criteria}

1) Previously treated patients.

2) Other malignancy.

3) Distant metastasis.

4) Associated co-morbidities.

The protocol was approved by hospital's institutional ethical committee and all patients were properly informed and consented for treatment study.

In External Beam Radiotherapy (EBRT), a total dose of 50Gy is delivered to whole pelvis in daily fractions of $2 \mathrm{~Gy}$, five days per week. All patients were treated with concurrent chemotherapy with cisplatin (40 mg/m ${ }^{2}$ weekly). The ICBT was started just after completion of EBRT. The Fletcher-Suit applicator was used in this treatment.

Application of ICBT was performed on an outpatient basis. For ICBT simulation, orthogonal films of antero-posterior and lateral views were taken with the applicators inserted, and the position of point $\mathrm{A}$, bladder and rectal points were defined according to the Manchester method and ICRU 38 recommendations. The Linear Quadratic equation was used to calculate the dose to point $\mathrm{A}$ :
Biological effective dose (BED) at point $\mathrm{A}$ (alpha/beta $=10)$

\section{BED=D (1+d/alpha/beta)}

- For whole Pelvis RT, $\mathrm{BED}_{10}$ is$50(1+2 / 10)=60$ Gy

- $\quad$ For Arm A BED is- 22.5(1+7.5/10) =39.4 Gy

- For Arm B BED is- 27.5(1+5.5/10) =42.6 Gy

So the total BED to Arm A is 99.4 Gy and total BED to Arm B is 102.6 Gy.

\section{Equivalent dose for $2 \mathrm{~Gy}$ (EQD2) at point $\mathrm{A}$ (alpha/beta=10) EQD2=BED/ (1+2/alpha/beta) \\ - For whole pelvis RT, EQD2 is- 50Gy \\ - For Arm A, EQD2 is- 32.8Gy \\ - For Arm B, EQD2 is- 35.5Gy}

So the total EQD2 to Arm A is $82.8 \mathrm{~Gy}$ and total EQD2 to Arm B is $85.5 \mathrm{~Gy}$.

Patients were evaluated at $1^{\text {st }}, 3^{\text {rd }}, 6^{\text {th }}$ month and then at I year for local disease response \& occurrence of any acute and late reactions. Response was evaluated in terms of complete response (CR), partial response (PR), stable disease (SD) or progressive disease (PD) (OBJECTIVE RESPONSE IN SOLID TUMORS (WHO CRITERIA). Grading of normal tissue reactions was done by RTOG (Radiation Therapy Oncology Group).

\section{Results}

Table 1: Patient Characteristics

\begin{tabular}{|c|c|c|c|}
\hline & & \multicolumn{2}{|c|}{ No. of Patients (\%) } \\
\hline & & $\begin{array}{c}\text { Arm A } \\
25(100 \%)\end{array}$ & $\begin{array}{c}\text { Arm B } \\
25(100 \%)\end{array}$ \\
\hline \multirow[t]{2}{*}{ Age } & $\leq 50$ yrs & $10(40 \%)$ & $14(56 \%)$ \\
\hline & $>50 \mathrm{yrs}$ & $15(60 \%)$ & $11(44 \%)$ \\
\hline \multirow[t]{2}{*}{ Menopausal Status } & Premenopausal & $7(28 \%)$ & $11(44 \%)$ \\
\hline & Postmenopausal & $18(72 \%)$ & $14(56 \%)$ \\
\hline \multirow[t]{2}{*}{ No. of full term pregnancies } & $\leq 2$ & $6(24 \%)$ & $5(22 \%)$ \\
\hline & $>2$ & $19(76 \%)$ & $20(80 \%)$ \\
\hline \multirow[t]{3}{*}{ Smoking History } & Non-Smoker & $21(84 \%)$ & $21(84 \%)$ \\
\hline & Current Smoker & $1(4 \%)$ & $2(8 \%)$ \\
\hline & Former Smoker & $3(12 \%)$ & $2(8 \%)$ \\
\hline \multirow[t]{3}{*}{ ECOG } & 0 & $08(32 \%)$ & $10(40 \%)$ \\
\hline & 1 & $10(40 \%)$ & $11(44 \%)$ \\
\hline & 2 & $07(28 \%)$ & $04(16 \%)$ \\
\hline \multirow[t]{3}{*}{ FIGO STAGE } & $\mathrm{I}$ & $00(0 \%)$ & $01(4 \%)$ \\
\hline & II & $13(52 \%)$ & $15(60 \%)$ \\
\hline & III & $12(48 \%)$ & $09(36 \%)$ \\
\hline \multirow{3}{*}{ 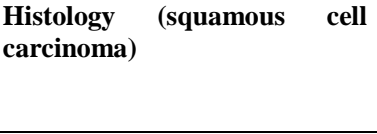 } & Well differentiated & $08(32 \%)$ & $12(48 \%)$ \\
\hline & $\begin{array}{c}\text { Moderately } \\
\text { differentiated }\end{array}$ & $11(44 \%)$ & $08(32 \%)$ \\
\hline & Poorly differentiated & $06(24 \%)$ & $05(20 \%)$ \\
\hline
\end{tabular}


Table 2: Treatment Response

\begin{tabular}{|c|c|c|c|c|c|c|c|c|}
\hline Disease Response & \multicolumn{4}{|c|}{$\operatorname{Arm~A~}$} & \multicolumn{4}{|c|}{ Arm B } \\
\hline & $\begin{array}{l}\text { At } 1^{\text {st }} \\
\text { month }\end{array}$ & $\begin{array}{l}\text { At } 3^{\text {rd }} \\
\text { month }\end{array}$ & At $6^{\text {th }}$ month & $\begin{array}{l}\text { At } 1^{\text {st }} \\
\text { year }\end{array}$ & $\begin{array}{l}\text { At } 1^{\text {st }} \\
\text { month }\end{array}$ & $\begin{array}{l}\text { At } 3^{\text {rd }} \\
\text { month }\end{array}$ & $\begin{array}{l}\text { At } 6^{\text {th }} \\
\text { month }\end{array}$ & $\begin{array}{l}\text { At } 1^{\text {st }} \\
\text { year }\end{array}$ \\
\hline $\begin{array}{l}\text { Complete Response } \\
\text { (CR) }\end{array}$ & 24 & 21 & 21 & 21 & 23 & 19 & 19 & 17 \\
\hline $\begin{array}{l}\text { Partial Response } \\
\text { (PR) }\end{array}$ & 01 & 00 & 00 & 01 & 02 & 00 & 00 & 00 \\
\hline $\begin{array}{l}\text { Stable Disease } \\
\text { (SD) }\end{array}$ & 00 & 00 & 00 & 00 & 00 & 00 & 00 & 00 \\
\hline $\begin{array}{l}\text { Progressive Disease } \\
\text { (PD) }\end{array}$ & 00 & 04 & 04 & 00 & 00 & 06 & 03 & 02 \\
\hline
\end{tabular}

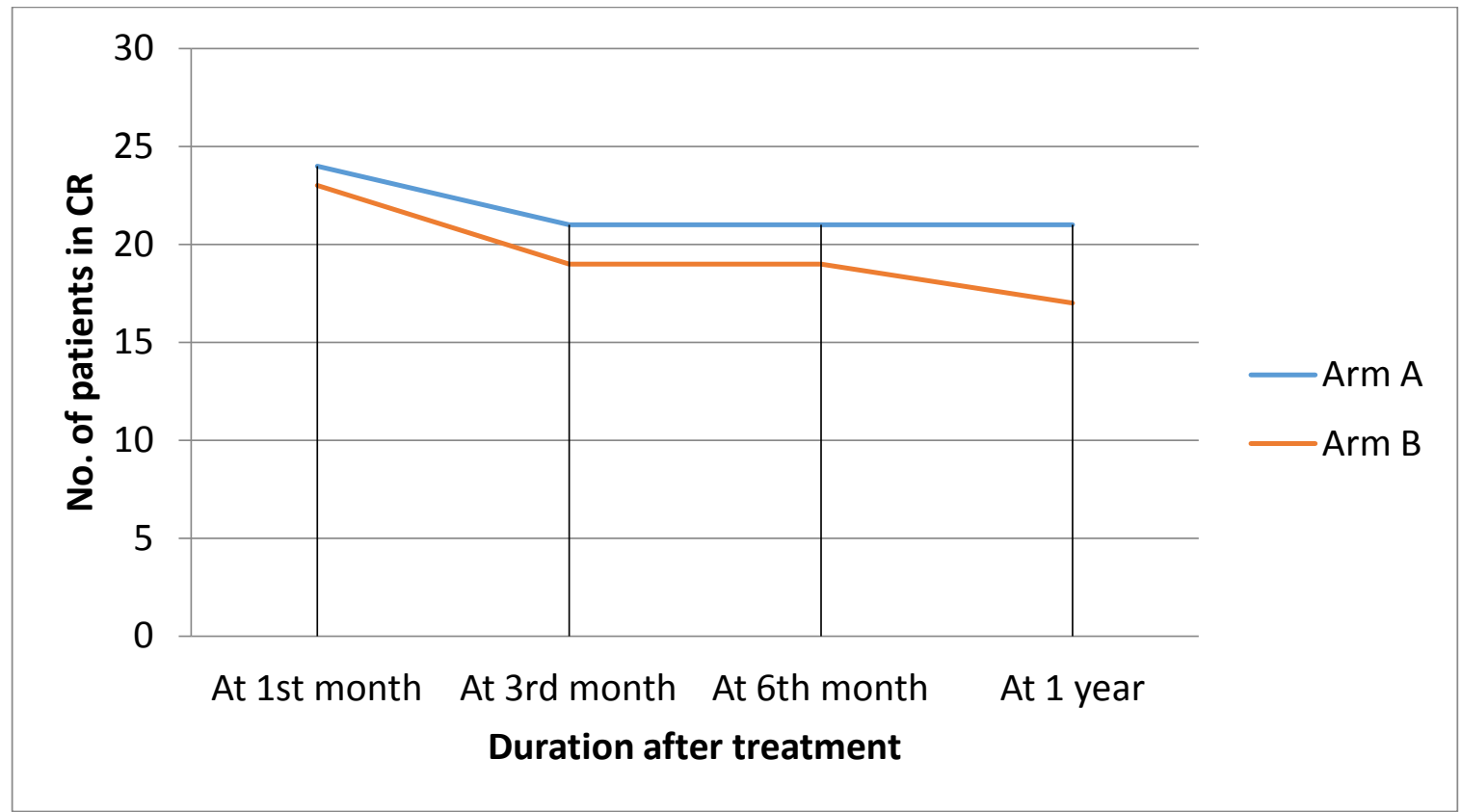

Figure 1: Line Diagram showing CR of two arms.

From the evaluation of 50 patients for treatment response by WHO criteria, 96\% in Arm A and $92 \%$ in Arm B shows complete response at $1^{\text {st }}$ month. At $3^{\text {rd }}$ and $6^{\text {th }}$ month, $84 \%$ in Arm A and
$76 \%$ in Arm B shows complete response. Others were either in partial response or progressive disease.

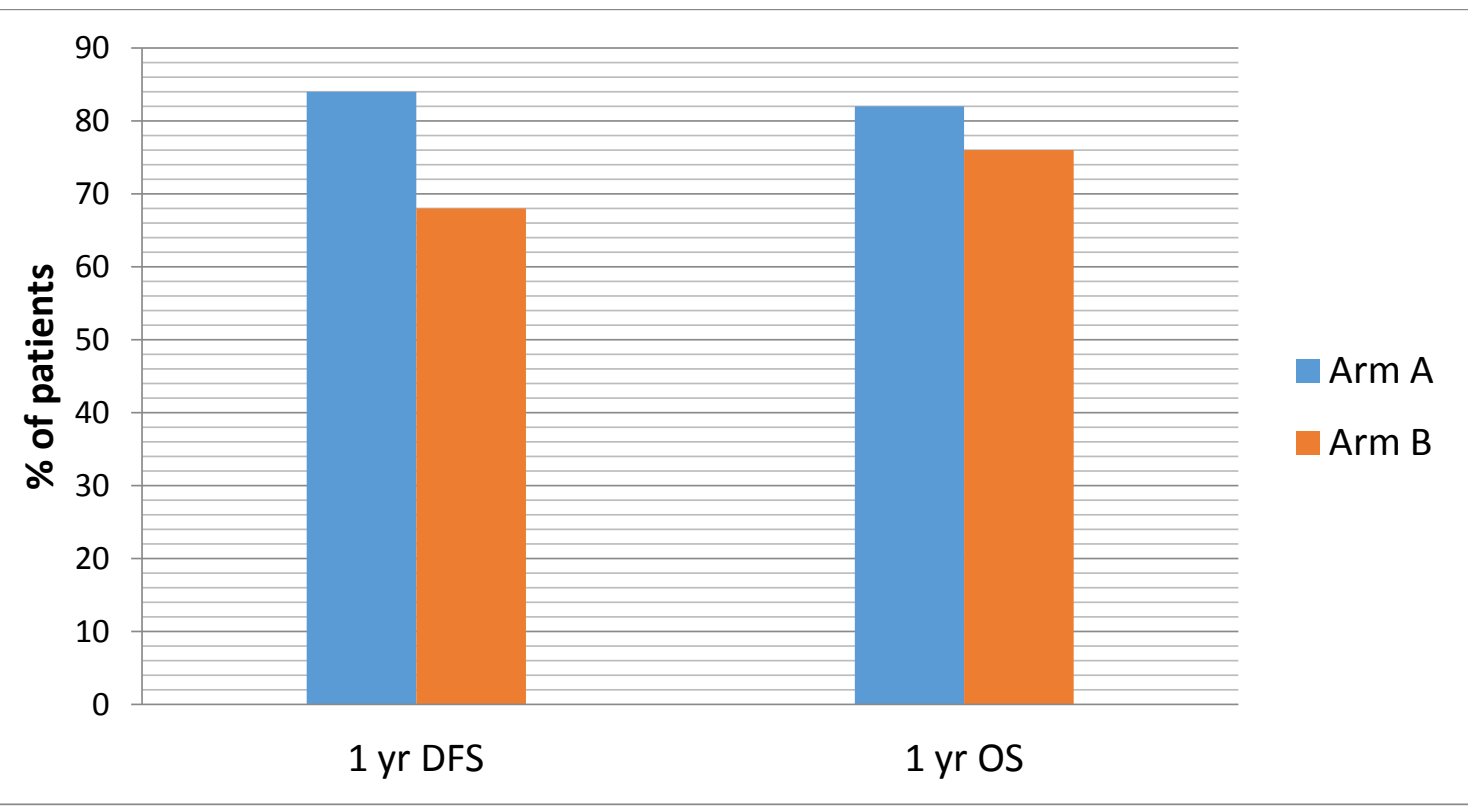

Figure 2: Graph showing DFS and OS of two arms 
1 year disease free survival (DFS) was $84 \%$ in Arm A and 68\% in Arm B. (p value=.185)

1 year overall survival (OS) was $88 \%$ in Arm A and $76 \%$ in Arm B. (p value $=.269$ )

This study showed no significant difference between the two arms.

Toxicities:- There was no statistical difference in grades of acute toxicities and they were managed accordingly and treatment need not to be stopped.
In haematological toxicity, $\mathrm{Hb}$ levels were measured. Grade III and IV haematological toxicity was seen in $12 \%$ in Arm A and $20 \%$ in Arm B. Acute skin toxicity in the form of grade III and IV was seen in $8 \%$ in Arm A and $0 \%$ in Arm B. Nausea and vomiting were manageable and no grade III and IV toxicity was seen in any arm. Diarrhoea of grade III and IV was observed in $8 \%$ in Arm A and 4\% in Arm B at the end of treatment.

Table 3: Late Toxicities

\begin{tabular}{|c|c|c|c|c|c|c|c|c|c|}
\hline S. No. & Late Complications & \multicolumn{4}{|c|}{$\operatorname{Arm~A}$} & \multicolumn{4}{|c|}{ Arm B } \\
\hline & & Grade I & Grade II & Grade III & Grade IV & Grade I & Grade II & Grade III & Grade IV \\
\hline 1 & Rectal Complications & 03 & 02 & 00 & 01 & 04 & 01 & 01 & 00 \\
\hline 2 & Bladder Complications & 05 & 00 & 00 & 00 & 04 & 00 & 00 & 02 \\
\hline 3 & Vaginal Fibrosis & 02 & 02 & 03 & 01 & 02 & 00 & 03 & 01 \\
\hline
\end{tabular}

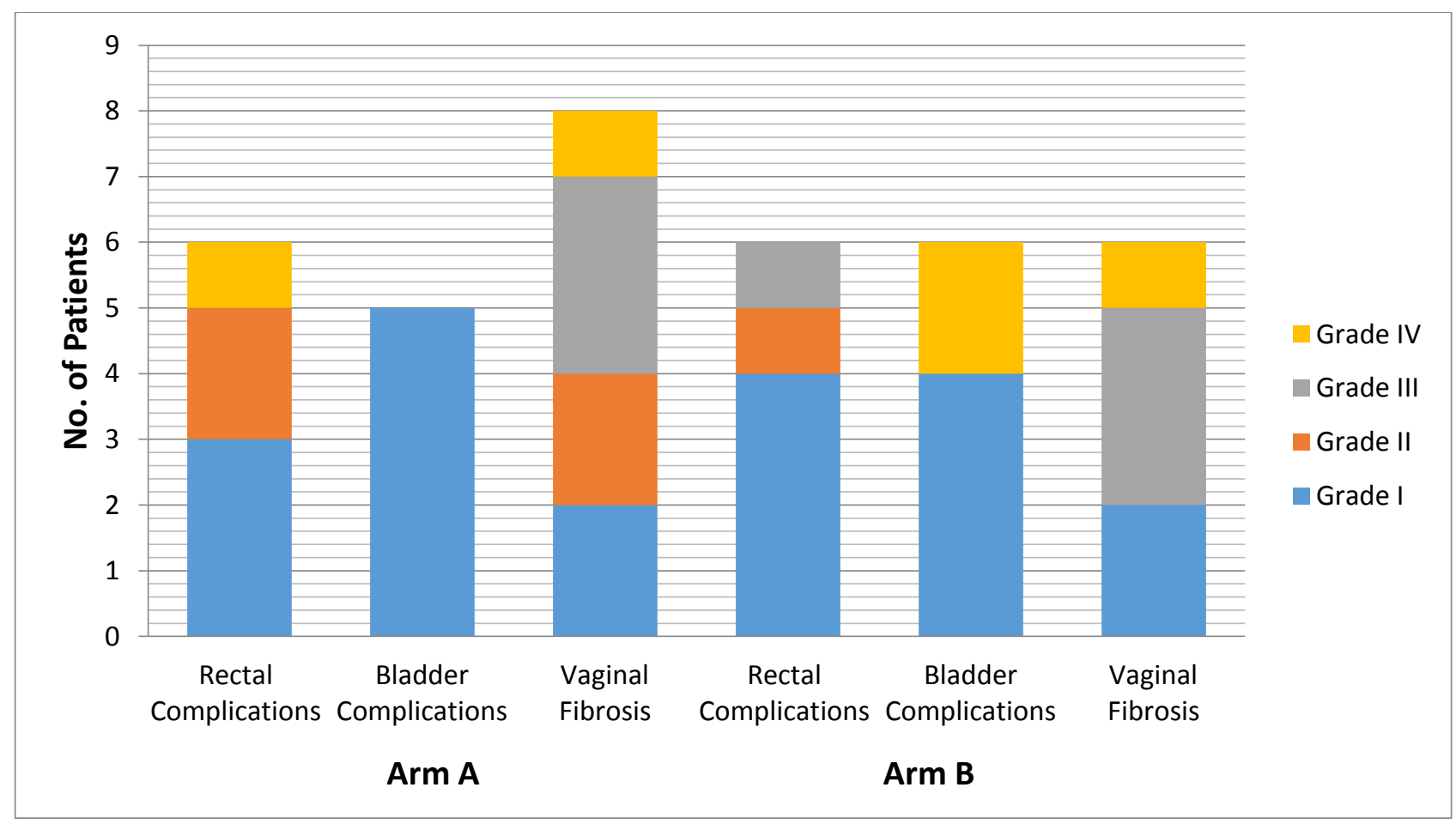

Figure 3: Graph showing late toxicity.

The most common late complication observed was vaginal fibrosis. Grade III and IV vaginal fibrosis were seen in $16 \%$ in both arms. Grade III and IV rectal complications were seen in 2 cases $(4 \%)$ of the study population ( 1 in each arm) ( $\mathrm{p}$ value=1). 1 patient complained of RVF in Arm A and 1 patient in Arm B complained of severe proctitis. Grade III and IV bladder complications in the form of VVF were observed in 2 cases $(4 \%)$ in Arm B.

\section{Discussion}

Use of radiotherapy for the management of cervical cancer is well documented. Combining EBRT with brachytherapy is highly effective for management of cervical cancer. Brachytherapy escalates dose at local site which is associated with low recurrence rate and improved overall survival. ${ }^{[11]}$

Literature supports that the most common age of presentation is mid 50's. In our study, $48 \%$ 
patients were in $<50 \mathrm{yrs}$ of age, in which $75 \%$ of patients were able to achieve CR and $52 \%$ patients were of $>50$ yrs of age, from which $77 \%$ achieved CR. Thus, this study showed that age does not affect disease response in cervical cancer patients. Results were similar with study results of Ying Gao et al., 2013. ${ }^{[12]}$

$36 \%$ patients were pre-menopausal and $64 \%$ were post menopausal.

While comparing number of full term pregnancies in study population, $22 \%$ patients were having $\leq 2$ full term pregnancies and patients having $>2$ pregnancies were $78 \%$. So, this study proved that full term pregnancy is a major factor of cervical cancer.

In present study, all $100 \%$ patients were histologically proven of squamous cell carcinoma, from which the most common is moderately differentiated carcinoma. From which, $85 \%$ of well differentiated, $79 \%$ of moderately differentiated and $82 \%$ of poorly differentiated carcinoma achieved CR. Similar results were obtained by Afsana Shah et al., 2018. ${ }^{[13]}$

In this study, mostly patients were of FIGO stage II $(56 \%)$ and III (42\%) with ECOG of $1(42 \%)$ and pre treatment $\mathrm{Hb}$ level was of 10-12 $\mathrm{gm} \%$ $(46 \%)$.

At the end of 1 year, 38 patients $(76 \%)$ had CR. CR rate was $84 \%$ for Arm A and $68 \%$ for Arm B ( $\mathrm{p}$ value $=.185)$. In Arm A, 1 patient was in partial response with residual disease at local site. Out of 22 alive patients in Arm B, 17 (68\%) patients had $\mathrm{CR}, 2$ patients had progressive disease (1 patient showed failure at local site and 1 had distant metastasis at lungs and skin of nose). Cases with residual disease or distant metastasis were treated with further chemotherapy.

Results of this study are comparable to Bornala Sreenivasa Rao et al. ${ }^{[14]}$ study in which Arm A (6Gy/\# for 4\#) and Arm B (8Gy/\# for 3\#), local control and DFS was $90 \%$ in Arm A and $83.3 \%$ in Arm B at 2.5 years of follow up period.

1 year disease free survival (DFS) was $84 \%$ in Arm A and 68\% in Arm B (p value=.185), which was not significant. 1 year overall survival (OS) was $88 \%$ in Arm A and $76 \%$ in Arm B (p value $=.269$ ). This study showed no significant difference in OS between the two arms. The cause of death was mainly due to residual disease and non compliant to further chemotherapy or metastatic disease to lungs and liver.

In a study of Chiang Mai et al., 2013, ${ }^{[15]}$ two arms of $7.2 \mathrm{~Gy} / \#$ for $3 \#$ and $6 \mathrm{~Gy} / \#$ for $4 \#$ were observed. At 3 yrs, local control, disease free survival and overall survival rate were $80.8 \%$, $63.4 \%, 98.8 \%$ in $7.2 \mathrm{~Gy}$ arm and $86.7 \%, 63.8 \%$ and $97.3 \%$ in $6 \mathrm{~Gy}$ arm respectively.

The late toxicity occurs in the form of vaginal fibrosis, rectal complications (proctitis, RVF) and bladder complication (VVF). There was no statistical difference in grades of toxicities in our study. At the end of 1 year, vaginal fibrosis was most common complication seen in patients. Grade III-IV vaginal fibrosis was $16 \%$ each in both arms. Rectal complications of Grade III-IV were observed in $4 \%$ each in both arms. 1 patient complained of RVF in Arm A and 1 patient in Arm B complained of severe proctitis. Bladder complications in the form of VVF was observed in $8 \%$ of Arm B only.

In a study by Gogia $\mathrm{P}$ et Al., 2017 ${ }^{[16]}$ HDR brachytherapy regimens of Group I: 6 Gy $\times 3$ fractions (weekly) and Group II: 5 Gy $\times 4$ fractions (biweekly). At 1 year of follow up, grade 2-3 rectal reactions in Group I were significantly higher than Group II, $6.65 \%$ versus nil ( $\mathrm{p}=$ 0.038 ). Grade 2 bladder toxicity was higher in group I, $3 \%$ versus $0 \%$.

\section{Conclusion}

To conclude, brachytherapy is an essential part of treatment of cervical cancer. Various dose and fractionation schedules have been tried by different institutes. In the present study both the regimes were found to be safe and well tolerated by patients. Arm A proved to be superior than Arm B on the basis of disease response and toxicities. But results were statistically not significant. So, any of the regimens can be used depending upon patient factors and work-load of 
the institute. Though for concrete assessment of disease response and toxicities, longer follow-up and a larger patient sample is required.

\section{References}

1. Maheshwari A, et al. Gynecological cancers: A summary of published Indian data. South Asian J Cancer. 2016 Jul-Sep; 5(3): 112-120.

2. GLOBOCON 2018. http://gco.iarc.fr/today/data/factsheets/populat ions/356india-fact-sheets.pdf

3. Burden of HPV related cancers. Human Papillomavirus and Related Diseases Report India. http://www.hpvcentre.net.

4. https://www.webmd.com.

5. Jain A, Ganesh B, Bobdey SC et al. Sociodemographic and clinical profile of cervical cancer patients visiting in a $\mathrm{TCH}$ in India. Indian Journal of Medical and Paediatric Oncology 2017 jul - sep;38(3): $291-295$.

6. Nag S, et al. The American Brachytherapy Society recommendations for High-dose-rate brachytherapy for carcinoma of the cervix. Int. J. Radiation Oncology Biol. Phys. 2000;201-211.

7. Viswanathan AN, Creutzberg CL, Craighead $\mathrm{P}$, et al. International brachytherapy practice patterns: a survey of the Gynecologic Cancer Intergroup (GCIG). Int J Radiat Oncol Biol Phys 2012;82(1):250-255. Copyright (C) 2012 Elsevier.

8. American Brachytherapy Society consensus guidelines for locally advanced carcinoma of the cervix. Part I: General principles, https://www.americanbrachytherapy.org/ABS /documentserver/?cfp=ABS/assets/file/public/guidelines /Guidelines_Carcinoma_Cervix_Part1.pdf

9. Petereit DG, Sarkaria JN, et al. The adverse effect of treatment prolongation in cervical carcinoma. Int J Radiat Oncol Biol Phys 1995; 32:1301-1307.
10. Saptarshi Ghosh, Pamidimukalabramhananda Rao High-Dose-Rate Orthogonal Intracavitary Brachytherapy with 9 Gy/Fraction in Locally Advanced Cervical Cancer: Is it Feasible? Journal of Obstetrics and Gynecology of India 2015;66(Suppl 1):17.

11. Montana GS, Martz KL, Hanks GE. Patterns and sites of failure in cervix cancer treated in the USA in 1978. Int J Radiat Oncol Biol Phys. 1991;20(1):87-93.

12. Gao Y, Jin-lu M, et al. The evaluation of older patients with cervical cancer. Clinical Interventions in Aging 2013:8 783-788.

13. Shah A, Jena NK, et al. Role of Histopathological Differentiation as a Prognostic Factor for Treatment Response in Locally Advanced Squamous Cell Carcinoma Cervix Patients. Indian J Med Paediatr Oncol 2018; 39:282-6.

14. Bonala SR, Pranabandhu D, et al. A Comparative Analysis of Two Different Dose Fractionation Regimens of High Dose Rate Intracavitary Brachytherapy in Treatment of Carcinoma of Uterine Cervix: A Prospective Randomized Study. Journal of Clinical and Diagnostic Research. 2017 Apr, Vol-11(4): XC01-XC05.

15. Tharavichitkul E, Klunkin $P$, et al. The Effects of Two HDR Brachytherapy Schedules in Locally Advanced Cervical Cancer Treated with Concurrent Chemoradiation: A Study from Chiang Mai, Thailand. J. Radiat. Res., 53, 281- 287 (2012).

16. Gogia P, Dhull AK, Kaushal V. Weekly versus biweekly high-dose rate brachytherapy schedules in carcinoma cervix following concomitant chemoradiation with paclitaxel and carboplatin. Asian J Oncol 2017; 3:12-16. 